\title{
HEMATOLOGICAL CHANGES AFTER INTRODUCTION OF DIFFERENT SIZES LEAD NANOPARTICLES (IN EXPERIMENT)
}

DOI: 10.36740/WLek202009216

\author{
Inna V. Gubarr ${ }^{1,2,3}$, Olena L. Apykhtina ${ }^{2}$, Oleksandr P. Yavorovsky' ${ }^{1}$, Oleksandr I. Kovalchuk ${ }^{3}$, Svitlana M. Chukhray' ${ }^{1}$ \\ Liudmyla M. Sokurenko ${ }^{1,3}$ \\ 'BOGOMOLETS NATIONAL MEDICAL UNIVERSITY, KYIV, UKRAINE \\ 2STATE INSTITUTION KUNDIIEV INSTITUTE OF OCCUPATIONAL HEALTH OF THE NATIONAL ACADEMY OF MEDICAL SCIENCES OF UKRAINE, KYIV, UKRAINE \\ 3EDUCATIONAL AND SCIENTIFIC CENTER "INSTITUTE OF BIOLOGY AND MEDICINE" OF TARAS SHEVCHENKO NATIONAL UNIVERSITY OF KYIV, KYIV, UKRAINE
}

\begin{abstract}
The aim: Was to compare the changes in hematological parameters of blood in the conditions of prolonged exposure of lead sulfide nanoparticles (NP) of different sizes and of lead nitrate.

Materials and methods: The study was conducted on mature male Wistar rats $160-180 \mathrm{~g}$, intraperitoneally injected with $\mathrm{Pb}\left(\mathrm{NO}_{3}\right)_{2}$ and $\mathrm{NP}$ PbS of 26-34 nm and 50-80 nm in 0,94 $\mathrm{mg} / \mathrm{kg} /$ day dose adjusted to lead. Toxic effects were evaluated after 1,5 months, 3 months and 1 month after exposure. The studies were performed on hematologic analyzer. Results: Changes in peripheral blood were characterized by decrease in the hemoglobin level in the blood. An increase in the total number of leucocytes was observed, which is statistically significant by the increase of number of lymphocytes and the absolute number of monocytes. Changes in the platelet number were characterized by an increase in the average volume of platelets and a decrease in the platelet heterogeneity index.

Conclusions: The most pronounced changes hemoglobin level in the blood and concentration of hemoglobin in the erythrocyte were observed in the effects of PbS NP (50-80 $\mathrm{nm})$, but leucocytes indicators - of PbS NP (26-34 nm) and Pb( $\left.\mathrm{NO}_{3}\right)_{2}$.
\end{abstract}

KEY WORDS: lead, nanoparticles, hematological parameters, hematotoxic effect

Wiad Lek. 2020;73(9 p. II):1982-1989

\section{INTRODUCTION}

Among the chemicals that pollute objects of the environment, heavy metals and they compounds form a significant group of toxicants [1 - 6]. Lead, as one of the most widespread and highly toxic metals, is included by World Health Organization and other international organizations in the list of global pollutants. The toxic effect of lead and its compounds on the body is manifested predominantly by damage to the nervous, cardiovascular, blood and kidney systems, and a violation of porphyrin metabolism [7 - 11].

A classic manifestation of the negative effects of lead on the body is the development of anemia due to damage to the organs of the hematopoiesis. It is known that lead that has got into the respiratory tract and/or into the gastrointestinal tract, enters to the bloodstream after a few minutes. Blood cells are among the first to get the negative impact of lead.

Lead, even in the short-term intake in the body at relatively low doses, causes a pronounced hematotoxic effect characterized by a violation of hemopoiesis and morphofunctional changes in all of the formed blood elements, the result of which is the emergence of anemia and the development of hypoxia in the organism, activation of free radical oxidation and oxidative stress, which causes the implementation of vaso-toxic action of the metal [12,13].
The development of nanotechnology is a promising industry in the modern information world [14]. When the particles of lead compounds are reduced to nanometers, their optical and quantum-chemical properties change significantly which contributes to the widespread implementation of nanoparticles (NP) of lead compounds in various industries and provides an opportunity to improve already existing as well as create more sensitive devices [15].

Lead sulfide in a nanocrystalline state has been widely used in infrared optics as a material for the manufacture of temperature-sensitive sensors, detectors, photoconductors, selective sensors; in flexible optoelectronics - high-performance photodetectors; in solar elements of the third generation in the form of quantum dots, which greatly increases the efficiency of the transformation of solar energy; as well as in a variety of polymer films and nanoporous matrices [16, 17].

However, the widespread use of specific properties of lead nanoparticles and its compounds not only opens up new perspectives, but can also pose a danger both to human health and to the environment [18 - 21]. The lack of thorough knowledge about the degree of lead nanoparticles toxicity and its potential danger to the organism requires a wide range of medical and biological research [22 - 24], in particular, the study of hematotoxic activity in evaluating the toxic properties of new compounds and NP which containing lead. 


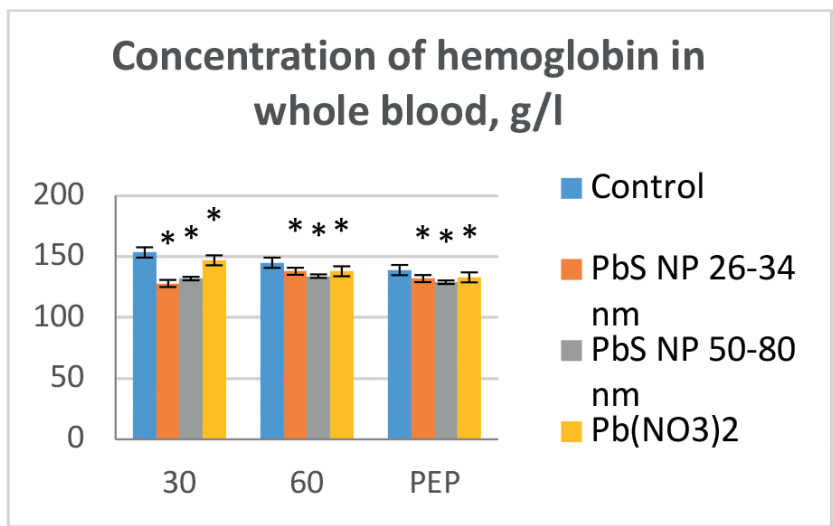

(a)

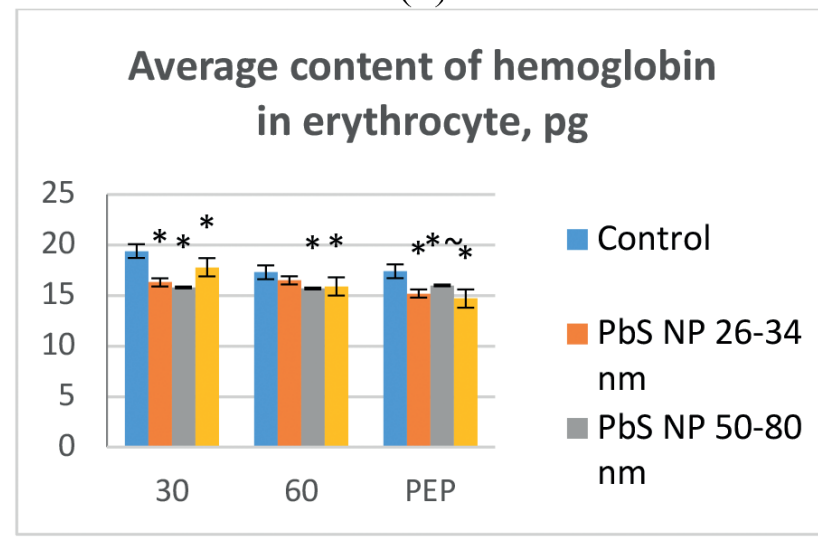

(c)

The average volume of erythrocytes, $\mu \mathrm{m}^{3}$

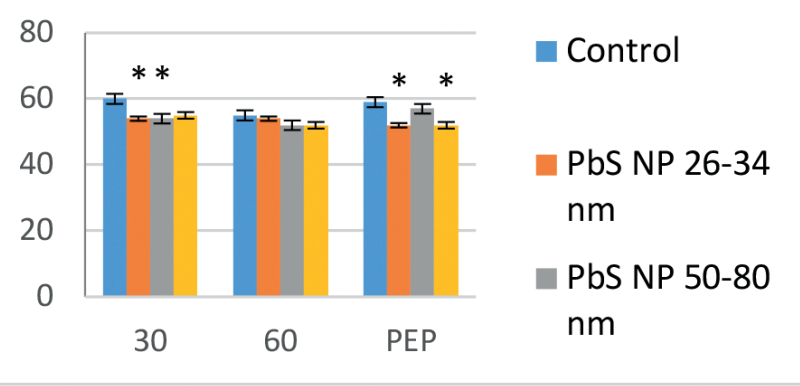

(e)

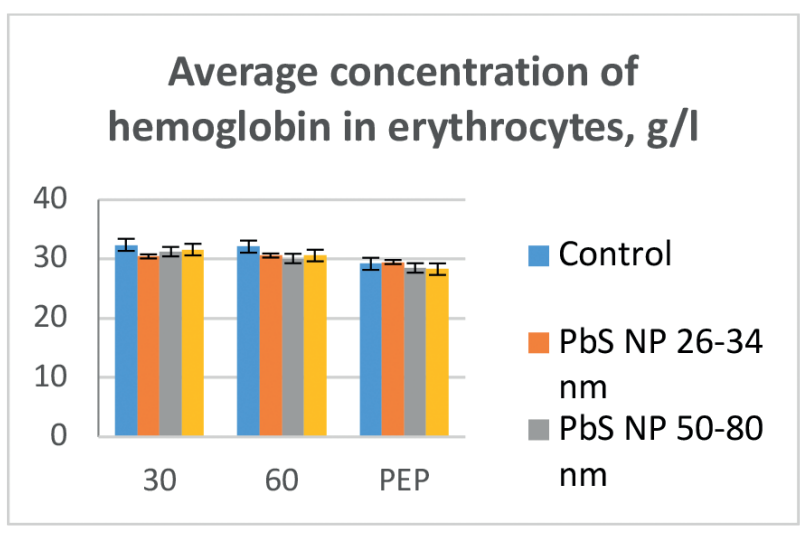

(b)

The number of erythrocytes, $10^{6} / \mathrm{ml}$

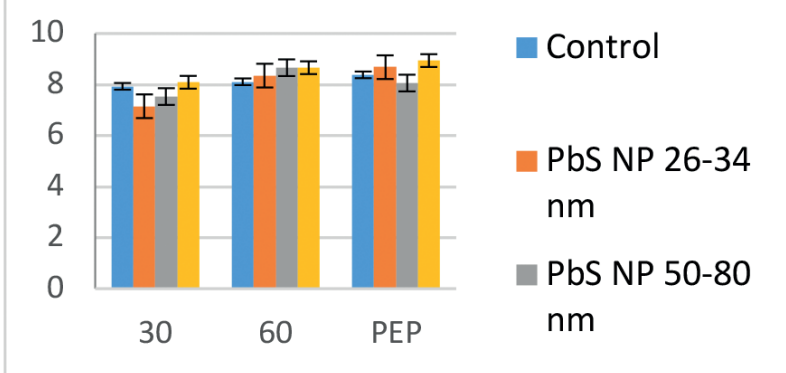

(d)

\section{Indicator of heterogeneity of erythrocytes, cu}

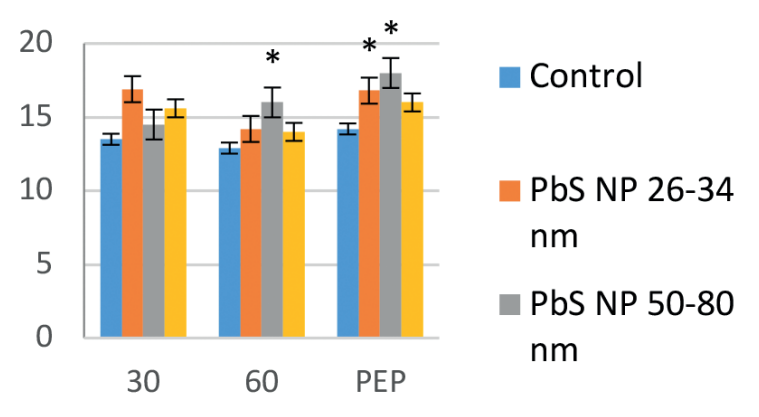

(f)

Note: * - statistically significant differences between the rates of animals in experimental groups from and of the control group; \# - statistically significant differences between the indicators of the groups of animals exhibited by lead sulfide NP of different sizes; - statistically significant differences between the indicators of the groups of animals exhibited by lead sulfide NP and lead nitrate.

Figure 1. Changes in parameters of the erythrocytes of peripheral blood cells of experimental animals.

\section{THE AIM}

The aim of the study was to compare the changes in hematological parameters of blood of experimental animals in the conditions of prolonged exposure of lead sulfide NP of various sizes and lead nitrate (ionic form).

\section{MATERIALS AND METHODS}

In this work are used lead compounds in nanoform: NP of lead sulfide (NP PbS) with 26-34 $\mathrm{nm}$ and $50-80 \mathrm{~nm}$ average size and in ionic form: lead nitrate $\left(\mathrm{Pb}\left(\mathrm{NO}_{3}\right)_{2}\right)$ which is readily soluble in water. Lead sulfide NP was obtained by 


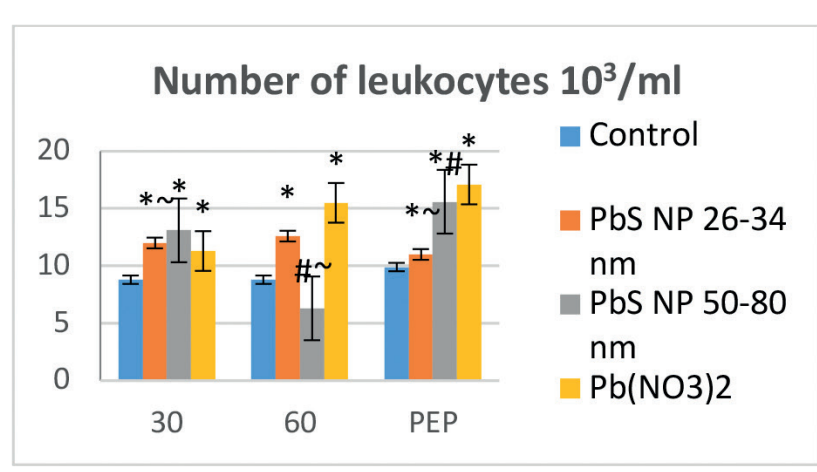

(a)

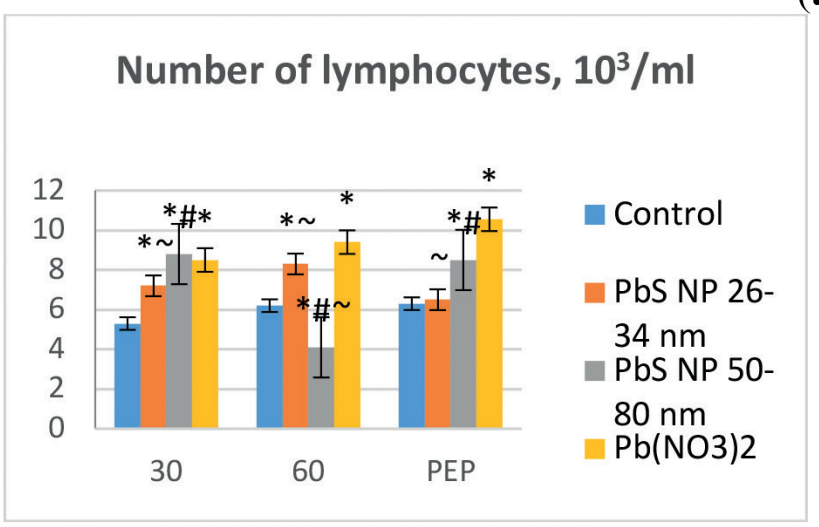

(b)

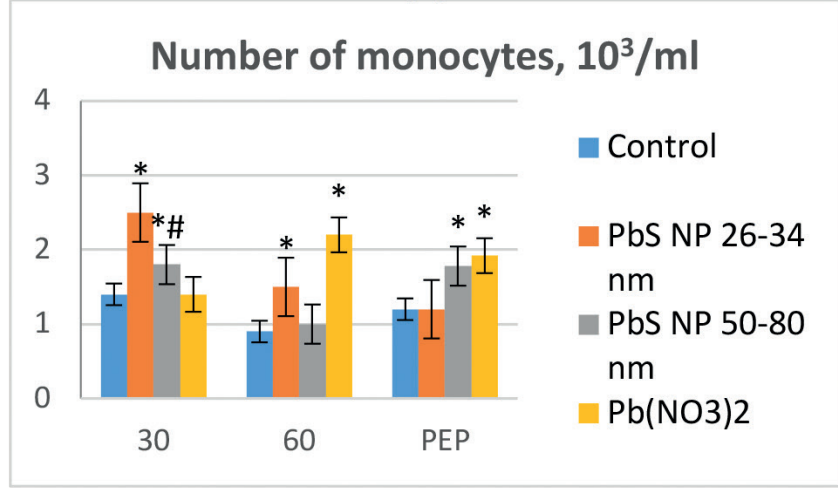

(d)

Number of granulocytic leukocytes,

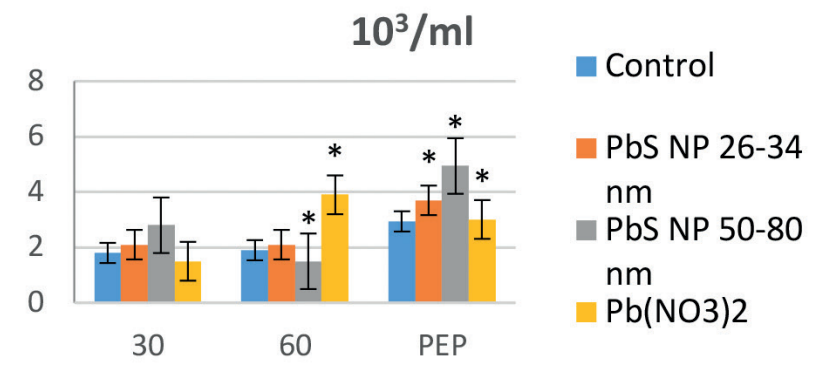

(f)

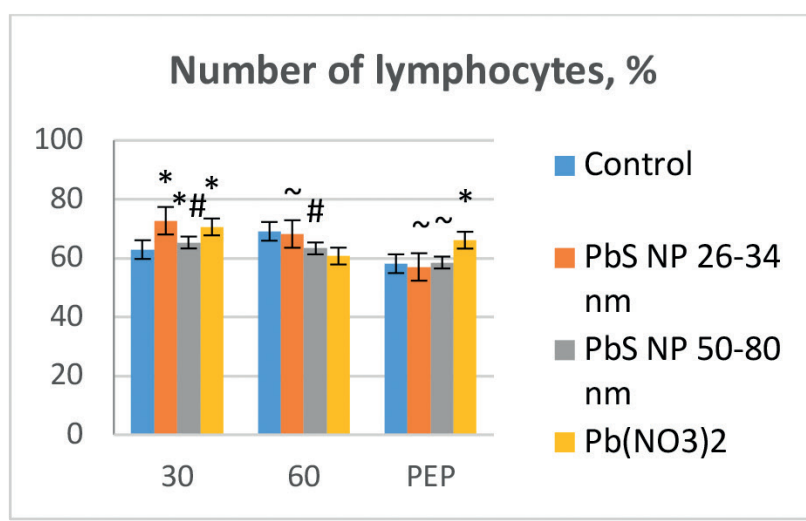

(c)

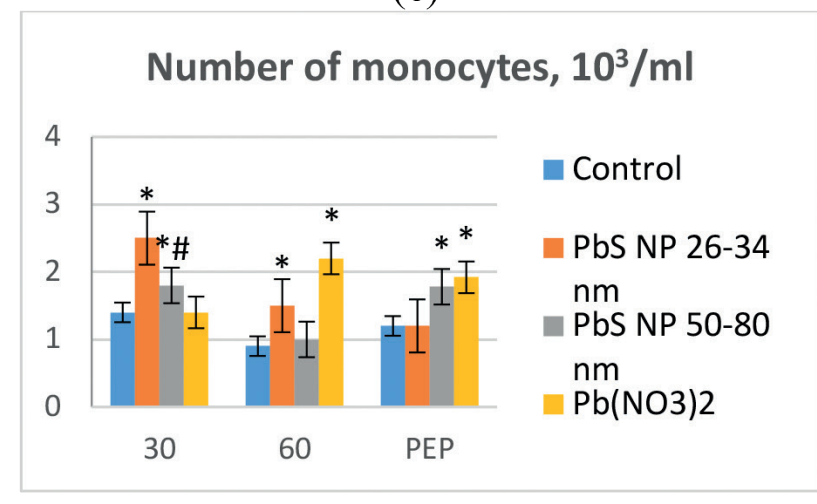

(e)
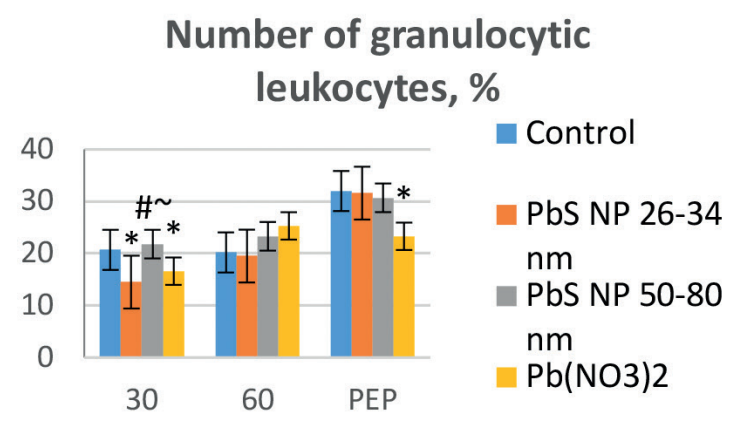

(g)

Note: * - statistically significant differences between the rates of animals in experimental groups from and of the control group; \#-statistically significant differences between the indicators of the groups of animals exhibited by lead sulfide NP of different sizes; - statistically significant differences between the indicators of the groups of animals exhibited by lead sulfide NP and lead nitrate.

Figure 2. Changes in the parameters of the leukocytes of peripheral blood cells of experimental animals. 


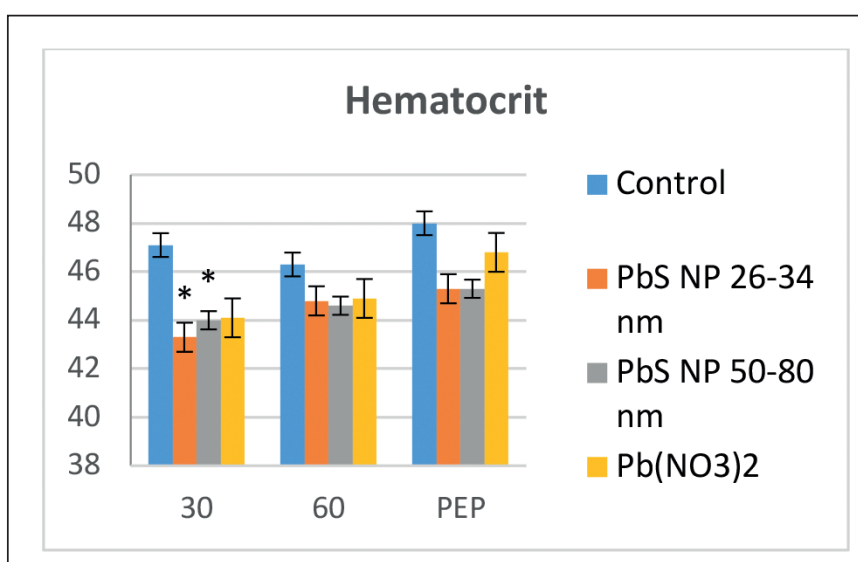

(a)

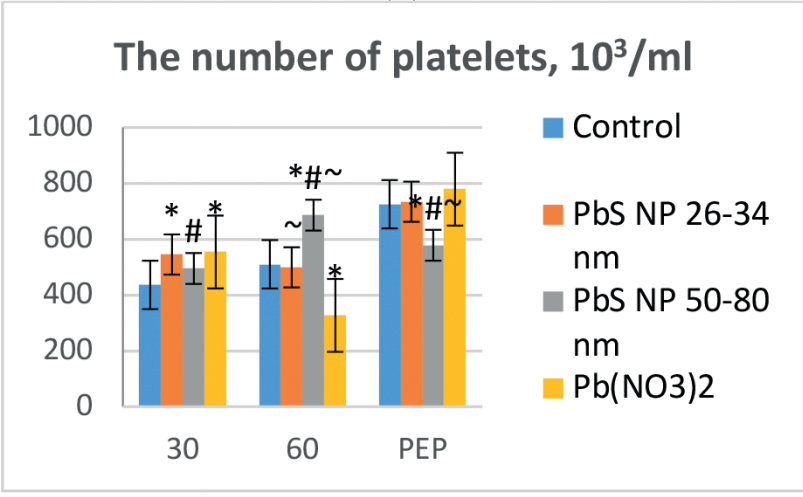

(c)

\section{Trombocritis}

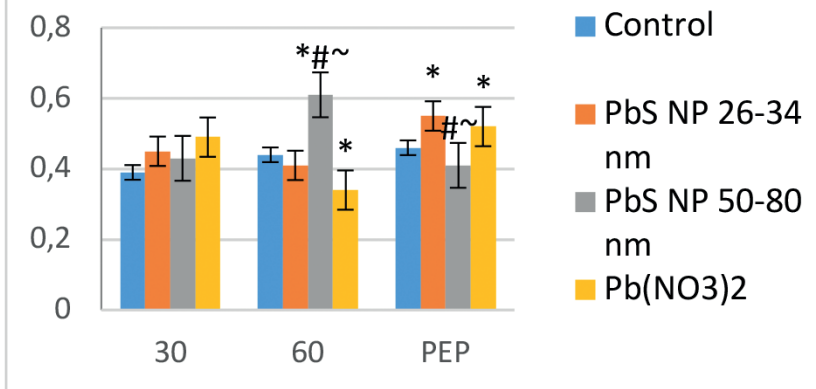

(b)

\section{Average volume of platelets, $\mu \mathrm{m}$}

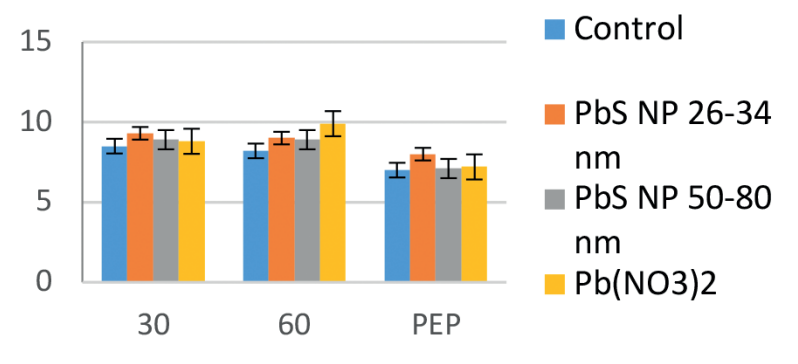

(d)

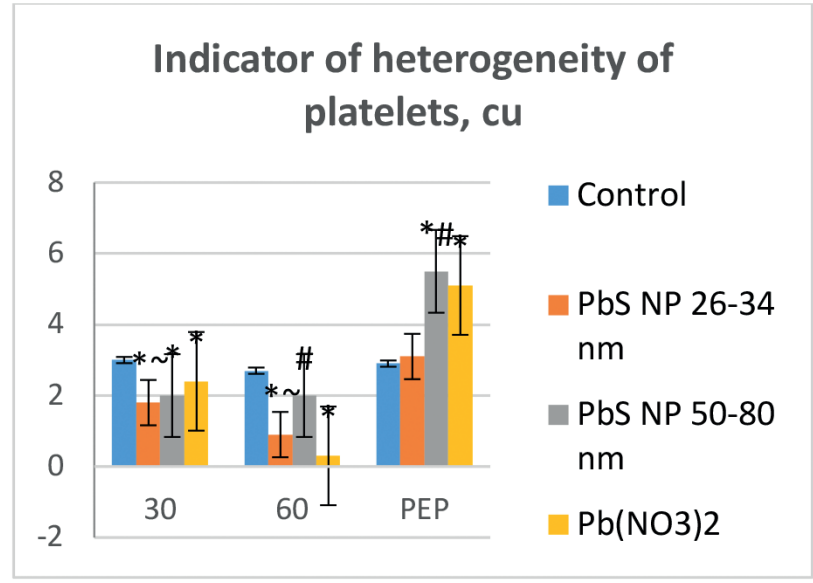

(e)

Note: * - statistically significant differences between the rates of animals in experimental groups from and of the control group; \#- statistically significant differences between the indicators of the groups of animals exhibited by lead sulfide NP of different sizes; - statistically significant differences between the indicators of the groups of animals exhibited by lead sulfide NP and lead nitrate.

Figure 3. Changes in hematocrit and platelets of peripheral blood levels of experimental animals.

chemical synthesis using a sodium polyphosphate stabilizer $\left(\mathrm{NaPO}_{3}\right)_{\mathrm{n}}$. NP size was determined by electron microscopy.

The study was conducted on mature male Wistar rats 160-180 g. The animals were kept in vivarium on a standardized diet with free access to drinking water. The rats were divided into 3 experimental groups and control group. The first experimental group was injected with NP $\mathrm{PbS} 26-34 \mathrm{~nm}$ in size, the second - NP PbS 50-80 nm in size, the third - with $\mathrm{Pb}\left(\mathrm{NO}_{3}\right)_{2}$; the control group received a physiological solution. These substances were administered intraperitoneally daily 5 times a week (simulation of a working week) in $0,94 \mathrm{mg} / \mathrm{kg} /$ day dose adjusted to lead. Toxic effects were evaluated after 30 injections (1.5 months) and 60 injections ( 3 months) - subchronic experiment and in the postexposure period (1 month after cessation of exposure). The blood was taken immediately after decap- 
itation. The studies were performed on the ABX MICROS 60 hematologic analyzer in accordance with the manufacturer's instructions. Statistical processing of primary data was carried out using the program Microsoft Excel 2003 and SPSS 21.0. Statistical significance of differences between indices was evaluated by Mann-Whitney U-test.

The studies were performed within the frame of research of State Institution Institute for Occupational Health of NAMS of Ukraine: «Comparative toxicity of micro- and nanoparticles of lead in experiments in vitro and in vivo (to the problem of improving the principles and methods of toxicological and hygienic studies of heavy metals)» (State registry number 0110U000299), «Investigation of the toxic effects of heavy metal nanoparticles, search and substantiation of preventive measures » (State registry number 0116U000497).

All manipulations with animals were carried out in accordance with the provisions of European Convention for the Protection of Vertebrate Animals used for Experimental and Other Scientific Purposes (Strasbourg, 1985). The study meets bioethical requirements. The experiment plan is approved by the Bioethics Commission State Institution «Institute for Occupational Health of NAMS of Ukraine, Kyiv» (Minutes № 5, session of bioethics commission from 23.11.2017).

\section{RESULTS}

The results of conducted experimental studies indicate that after subchronic experiment of lead compounds to experimental animals there were changes in the erythrocytes (fig. 1). A statistically significant reduction of hemoglobin concentration in blood (compared to the corresponding indicators of control group) was detected after the injection of lead nitrate and lead sulfide in the form of nanoparticles, which may indicate a violation of the heme synthesis processes.

In the post-exposure period (PEP), hemoglobin level was also reduced in all three experimental groups. After subchronic experiment of lead compounds to rats, the average content of hemoglobin in erythrocyte (per unit volume of the cell) was significantly lower in animals of all three experimental groups, moreover with action of the NP $\mathrm{PbS}$ this indicator was significantly lower than with action of lead nitrate. One month after the cessation of exposure, a significant decrease in this index was observed in animals exposed of lead nitrate and NP PbS with smaller size (26-34 nm).

In animals, exposed with studied lead compounds in nano- and ionic forms, there were no statistically significant changes in the number of erythrocytes.

The average volume of erythrocytes in the first study period was reduced in the blood of animals of all three experimental groups compared with control parameters indicating the outflow in the vascular bed of functionally immature erythrocytes. After the recovery period (1 month), the average volume of erythrocytes was statistically significantly lower in animals exposed of lead nitrate and of $\mathrm{NP} \mathrm{PbS}$ with smaller size.
Indicator of heterogeneity of erythrocytes which characterizes the degree of heterogeneity of erythrocytes by their size, was increased in animals of all three experimental groups compared with the control group. NP PbS of 50$80 \mathrm{~nm}$ caused more pronounced statistically significant morphological changes in red blood cells of animals than other compounds.

In the post-exposure period, the erythrocyte heterogeneity index was also elevated in the blood of animals in all three experimental groups compared with the control parameters, but was most changed by the action of $\mathrm{PbS}$ NP of larger size. Thus, changes in the erythrocyte series of blood cells of rats exposed of PbS NP of different sizes were characterized by a decrease of hemoglobin level in the blood, a decrease in the content and concentration of hemoglobin in the erythrocyte, which indicates a violation of the processes of hemoglobin synthesis

Reducing the volume of red blood cells and increasing the heterogeneity of erythrocytes indicates the violation of the erythropoiesis processes and the output in the vascular bed of functionally immature and poor on hemoglobin erythrocytes. The most pronounced changes in the blood of rats were observed with the effect of PbS NP with larger size compared with smaller PbS NP and lead nitrate.

Indicators of leukocyte series of peripheral blood cells of rats after exposure to lead compounds were characterized by certain changes (Fig. 2).

In animals there was a tendency to increase the number of leukocytes in comparison with the control group, but it was not statistically significant. The number of lymphocytes in the blood, both absolute and relative, increased statistically significantly after 30 days of exposure in animal from experimental groups, but the most significant changes occurred after injection of a smaller PbS NP and lead nitrate. In the post-exposition period, there was a normalization of the level of lymphocytes in the blood of experimental groups of rats relative to the control group of animals. In the blood of rats exposed to PbS NP and lead nitrate, there was a statistically significant increase of the absolute number of monocytes, while the relative number of monocytes decreased, which was due to an increase in the number of lymphocytes in the leukocyte formula. At the end of the recovery period, in experimental rats of all groups there was observed approximation of the number of monocytes to control levels. There were no significant changes in the number of neutrophils in the experimental animals both after subchronic experiment and in the post-exposure period.

Hematocrit was statistically significantly lower in the blood of animals after exposure to lead compounds with respect to control in the first study period, and 1 month after the cessation of exposure was not statistically different from the control values. The rate of thrombocyte in the blood of animals in experimental groups was not statistically different from the rate of the control group in both research periods (Fig. 3).

The number of platelets in the first study period of the animals' blood exposed to lead compounds was not sta- 
tistically different from the control values. In the post-exposition period, platelet count decreased in animals after the introduction of a larger PbS NP. The average platelets volume in animal blood in experimental groups in both monitoring periods increased with respect to control, but a statistically significant change was observed in the rats exposed to smaller PbS NP.

The platelet heterogeneity index, which characterizes the thrombocytes volume distribution in the blood of animals in experimental groups, decreased with respect to control group in both studies, but these changes were statistically significant in the post-exposure period, especially in the effect of smaller PbS NP. An increase in the average volume of platelets is due to accelerated thrombocytopoiesis (young blood platelets have a larger volume), this is also confirmed by the decrease in platelet heterogeneity. Thus, changes by the effects of a smaller PbS NP after the restoration period are observed due to accelerated thrombocytopoiesis and the output of young, functionally immature blood platelets in the bloodstream. At the same time, these changes are adaptive in nature. After injections of larger PbS NP, these changes are less pronounced, and there is a decrease in platelet count. The latter indicates a breakdown of compensatory mechanisms and a more negative impact of the PbS NP on thrombocytopoiesis.

\section{DISCUSSION}

The obtained results allow to state that after injections of lead compounds, changes in the peripheral blood of rats were characterized by a decrease in the level of hemoglobin in the blood, decrease in the content and concentration of hemoglobin in the erythrocytes indicating a violation of the processes of hemoglobin synthesis and a decrease in the volume of erythrocytes and an increase in the heterogeneity of erythrocytes, that indicates a violation of the processes of erythropoiesis and the exit to the vascular bed of the functionally immature erythrocytes poor on hemoglobin. The most pronounced changes in the peripheral blood of rats were observed in the effects of PbS NP with a larger size (50-80 nm) compared to a smaller PbS NP (26-34 nm) and lead nitrate (ionic form).

Indicators of the leukocyte series of peripheral blood cells of rats were characterized by a slight increase in the total number of leukocytes, significant increase in the absolute and relative number of lymphocytes and the absolute amount of monocytes. The most significant changes occurred after injections of a smaller PbS NP and lead nitrate.

Changes in the platelet count of blood cells were characterized by an increase in the average volume of platelets and a decrease in the platelet heterogeneity index. Under the influence of PbS NP $(26-34 \mathrm{~nm})$ in the post-expositional period, changes are observed due to accelerated thrombocytopoiesis and the release of young, functionally immature blood platelets to the bloodstream. At the same time, these changes were adaptive in nature. These effects were less pronounced under the influence of $\mathrm{PbS} \mathrm{NP}$ (50-80 $\mathrm{nm})$, but there was a decrease in platelet count, indicating a breakdown of compensatory mechanisms and a more negative influence on thrombocytopoies.

The obtained data testify that the toxic effect of the $\mathrm{PbS}$ $\mathrm{NP}$ is conditioned by the negative influence of lead on the organism, which is consistent with the data on the study of the mechanism of its hematotoxic action [25]. The results of studies [26] show that lead inhibits enzymes of haem biosynthesis and alters haematological parameters of battery manufacturing workers, which confirms our experimental data (after injection of lead compounds, changes in the peripheral blood of rats were also characterized by a decrease in hemoglobin levels in the blood, a decrease in the content and concentration of hemoglobin in the erythrocyte, a decrease in the volume of erythrocytes and an increase in the total number of leukocytes).

The results of our experimental studies on changes in the leukocyte series of peripheral blood cells of rats (increase in the number of monocytes and lymphocytes) were also confirmed in the data obtained by V.A. Kondratyuk [27] with oral administration of lead NP to rats at doses of 7 $\mathrm{mg} / \mathrm{kg}$ of body weight against the background of drinking water of various composition.

Toxicological studies of Asghar Amiri [28] shows increasing of $\mathrm{Pb}$ nanoparticles toxicity compared to micrometer particles of the same composition with a single intravenous injection of $\mathrm{PbO}$ and $\mathrm{PbO}-\mathrm{NPs}$ to rats at doses of $5 \mathrm{mg} / \mathrm{kg}$ of body weight (once a week for 8 consecutive weeks), which is consistent with our results.

The dynamics of the content of alanine aminotransferase (ALT) and aspartate aminotransferase (AsAT) in the blood serum of experimental animals demonstrates a statistically significant decrease in the activity of enzymes on 30 injections and increase on 60 injections. This is evidence of compensatory processes with toxic effects of $\mathrm{Pb}(\mathrm{NO} 3) 2$, $\mathrm{PbS} N \mathrm{~N}$ with a larger size $(50-80 \mathrm{~nm})$ and small size (26-34 $\mathrm{nm})$ on hepatocyte [29].

\section{CONCLUSIONS}

1 . The study was conducted on mature male Wistar rats in a subchronic experiment: 30 and 60 injections $\mathrm{Pb}(-$ $\left.\mathrm{NO}_{3}\right)_{2}$ and $\mathrm{PbS} \mathrm{NP}$ of 26-34 and 50-80 nm during 1,5 and 3 months five times a week in $0,94 \mathrm{mg} / \mathrm{kg} /$ day dose adjusted to lead and in the end of the recovery period (1 month) revealed a change in the hematological parameters of the animals.

2. After injections of lead compounds, changes in peripheral blood of rats were characterized by a decrease in hemoglobin levels in the blood, a decrease in the content and concentration of hemoglobin in the erythrocyte, indicating a violation of the processes of hemoglobin synthesis, and a decrease in the volume of erythrocytes and an increase in the heterogeneity of erythrocytes, that shows a violation of the processes of erythropoiesis and the exit to the vascular bed of the functionally immature erythrocytes poor on hemoglobin. The most pronounced changes in peripheral blood of rats were observed in the effects of PbS NP (50-80 nm) compared with smaller PbS $\mathrm{NP}(26-34 \mathrm{~nm})$ and $\mathrm{Pb}\left(\mathrm{NO}_{3}\right)_{2}$ (ionic form). 
3. For indicators of the leukocyte of peripheral blood cells of rats, a small increase in the total number of leukocytes was found, which is statistically significant with an increase in the absolute and relative number of lymphocytes and the absolute amount of monocytes. The most significant changes occurred after the introduction of $\mathrm{PbS} \mathrm{NP}$ (26-34) nm and $\mathrm{Pb}\left(\mathrm{NO}_{3}\right)_{2}$.

4. Changes in the platelet count of blood cells were characterized by an increase in the average volume of platelets and a decrease in the platelet heterogeneity index. Under the influence of PbS NP (26-34 nm) in the post-expositional period, changes were observed due to accelerated thrombocytopoiesis and the release of young, functionally immature blood platelets in the bloodstream. At the same time, these changes had a compensatory adaptive nature. By the effects of PbS NP (50-80 nm), these changes were less pronounced, however, there was a decrease in platelet count, indicating a breakdown of compensatory mechanisms and a more negative effect on thrombocytopoiesis.

\section{REFERENCE}

1. Apykhtina 0.L., Dybkova S.M., Sokurenko L.M., Chaikovsky Yu.B. Cytotoxic and genotoxic effects of cadmium sulfide nanoparticles. Exp Oncol 2018; 40(3): 194-199.

2. Sokurenko L.M., Chaikovskii Yu.B. Protective effects of Thiotriazolinum and Mildronate against mercury chloride toxicity in neuroblastoma cell culture Neurophysiology 2016;48(3): 171-175. https://doi.org/10.1007/ s11062-016-9585-7.

3. Sokurenko L.M., Chaikovskii Yu.B. Mildronate protects neuroblasts against toxic influence of mercuric chloride in cell culture. Neurophysiology, 2014; 46(3): 271-273. https://doi.org/10.1007/s11062-014-9440-7

4. Sokurenko L.M., Savchyna M.0., Litus V.I., Kaminsky R.F. et al. Rat spinal ganglia in assessment of protective action of antioxidants: A morphological study Medicina (Kaunas). 2017; 53(4): 217-223.

5. Lavrinenko V.E., Zinabadinova S.S., Shobat L.B., Sokurenko L.M. et al. Influence of nanodiamonds and carbon nanowires on survival and cells structure in chicken embryo. Georgian Medical News. 2016; 6 (255): 93-9.

6. Zinabadinova S., Lavrinenko V., Kaminsky R., Korsak A. et al. Effects of technogenic pollutants on chicken embryos. Curr Issues Pharm Med Sci, 2018;31(1):34-38.

7. Trakhtenberg I.M., Dmytrukha N.M., Lugovskyi S.P., Chekman I.S. et al. Lead is a dangerous pollutant. The old and new problem. Modern problems of toxicology, food and chemical safety. 2015; 3(71): 14-24.

8. Omelchuk S.T., Aleksijchuk V.D., Sokurenko L.M., Blagaia A. et al. Characteristics of rat liver exposed to nanoparticles of lead compounds. Georgian Med News, 2016; 261: 94-99.

9. Aleksiichuk V., Omelchuk S., Sokurenko L., Kaminsky R.et al. The influence of lead nanoparticles on the morpho-functional changes of rat liver during the postexposure period. Microsc Res Tech. 2018;81:781788. doi: 10.1002/jemt.23036.

10. Korbakova A.I., Sorkina N.S., Molodkina N.N. Lead and its effects on the body (literature review). Occupational Medicine and Industrial Ecology. 2001; 5: 29-34.

11. Ferreira de Mattos G., Costa C., Savio F., Alonso M. et al. Lead poisoning: acute exposure of the heart to lead ions promotes changes in cardiac function and Cav1.2 ion channels. Biophys Rev. 2017; 9(5): 807-825.
12. Kaminsky F.R., Sokurenko M. L., Chaikovsky B.Yu. Status of rats myocardium under subchronicmercury exposure and its pharmacological correction. Curr Issues Pharm Med Sci., 2016; 29(4):167-70

13. Kamynsky R., Primachenko V., Sokurenko L., Chaikovsky Y. A study of impact of mercury chloride on myocardium in experiment. Georgian Med News. 2016; 251: 64-70

14. Gusev A.I. Nanomaterials, nanostructures, nanotechnology. Fizmatlit, 2009: 416.

15. Sadovnikov S.I., Kozhevnikova N.S., Rempel A.A. The structure and optical properties of nanocrystalline lead sulfide films. Semiconductors. 2010; (44);10: 1349-1356.

16. Shmanova E.V., Bochenkov V.E., Sergeev G.B. Lead nanoparticles. Obtaining and Properties. Saarbrucken: LAP LAMBERT Academic Publishing $\mathrm{GmbH}$ and $\mathrm{C} 0 . \mathrm{KG}, 2011: 107$.

17. Akimov D.V., Andrienko O.S., Egorov N.B., Zherin I.I., Usov V.F. Synthesis and properties of lead nanoparticles. Russian Chemical Bulletin. 2012; 61(2): 225-229.

18. Trachtenberg I.M., Yavorovsky O.P., Zinchenko T.0., Shevtsova V.M. et al. New information from experience hygienic evaluation of high technology preparation nanometals and potential risks their influence on the workers. Likars'ka sprava. 2015; 1-2: 116-125.

19. Jeevanandam J., Barhoum A., Chan Y.S., Dufresne A. et al. Review on nanoparticles and nanostructured materials: history, sources, toxicity and regulations Beilstein J Nanotechnol. 2018; 9: 1050-1074.

20. Apykhtina 0.L. Features of toxic action of lead sulfide nanoparticles on the body, depending on their size. Journal of the National Academy of Medical Sciences of Ukraine. 2013; 19: 19-20.

21. Aleksijchuk V.D., Sokurenko L.M., Omelchuk S.T. Peculiarities of lead sulfide and nitrate nanoparticles influence on organisms of experimental animals in different research periods and methods of its negative impact correction. The world of medicine and biology. 2015; 4 (54): 97-101.

22. Yavorovsky 0.P., Tkachyshyn V.S., Arustamian 0.M., Kostuchenko A.M., Soloha N.V. Nanomaterials and nanoparticles: structure, physicochemical and toxicological properties, impact on the organism of the workers. Environment and health. 2016; 3: 29-36.

23. Krug H.F.. Nanosafety Research - Are We on the Right Track? Angewandte Chemie International Edition. 2014; 53: 12304-12319.

24. Apykhtina 0.L., Sokurenko L.M., Chaikovsky Yu.B., Shobat L.B., Bryuzgina T.S. Change of the content of fatty acids in brain tissues of animals after influence of nanoparticles of lead sulfide of different size. Science and Education: materials of the II international research and practice conference, Vol. II, Munich, Germany. 2012:438-442.

25. Apykhtina 0.L., Dmytrukha N.M., Kotsiuruba A.V., Korkach Yu. P. et al. Mechanisms of hematotoxic effects of lead compounds. Journal of the National Academy of Medical Sciences of Ukraine. 2012; 18(1): 100-109.

26. Kshirsagar M., Patil J., Patil A., Ghanwat G. et al. Effects of Lead on Haem Biosynthesis and Haematological Parameters in Battery Manufacturing Workers of Western Maharashtra, India. Journal of Pharmaceutical, Chemical and Biological Sciences. 2016; 3(4): 477-487.

27. Kondratiuk V.A., Fedoriv 0.Ye., Lototska 0.V. Effect of lead nanoparticles on the peripheral blood indices of experimental animals against a background of use potable water usage containing potassium and sodium stearates. Clinical and experimental pathology. 2013; 12 (4): 61-64.

28. Amiri A., Mohammadi M., Shabani M. Synthesis and toxicity evaluation of lead oxide ( $\mathrm{PbO}$ ) nanoparticles in rats. Electronic Journal of Biology, 2016, 12(2): 110-114. 
29. Omel'chuk S.T., Aleksiïchuk V.D., Sokurenko L.M. Biochemical parameters of blood and morpho-functional state of the liver of experimental animals by the actions of lead sulfide nanoparticles in different time study. Likars'ka sprava, 2014; 3-4: 114-118.

\section{ORCID and contributionship:}

Inna V. Gubar: 0000-0002-4105-5644 ${ }^{A, B, D}$

Olena L. Apykhtina: 0000-0003-3677-3921 ${ }^{\mathrm{C}}$

Oleksandr P. Yavorovskiy: 0000-0002-4573-8039 E, F

Olexandr I. Kovalchuk: 0000-0002-6311-3518 ${ }^{E}$

Svetlana N. Chuhray: 0000-0001-7431-7375 E

Liudmyla M. Sokurenko: 0000-0002-6870-2290 D, F

\section{Conflict of interest:}

The Authors declare no conflict of interest.

\section{CORRESPONDING AUTHOR}

\section{Inna V. Gubar}

Bogomolets National Medical University

13 T. Shevchenko st., 01601 Kyiv, Ukraine

tel: +380679838791

email: ginna5@ukr.net

Received: 09.09 .2019

Accepted: 25.06 .2020

A - Work concept and design, B - Data collection and analysis, C - Responsibility for statistical analysis, D-Writing the article, $\mathbf{E}$-Critical review, $\mathbf{F}$ - Final approval of the article 